\title{
Comparison of pregnenolone sulfate, pregnanolone and estradiol levels between patients with menstrually-related migraine and controls: an exploratory study
}

Cecilia Rustichelli ${ }^{1}$, Elisa Bellei ${ }^{2}$, Stefania Bergamini ${ }^{2}$, Emanuela Monari ${ }^{2}$, Flavia Lo Castro ${ }^{3}$, Carlo Baraldi ${ }^{4}$, Aldo Tomasi ${ }^{2}$ and Anna Ferrari ${ }^{4^{*}}$ (D)

\begin{abstract}
Background: Neurosteroids affect the balance between neuroexcitation and neuroinhibition but have been little studied in migraine. We compared the serum levels of pregnenolone sulfate, pregnanolone and estradiol in women with menstrually-related migraine and controls and analysed if a correlation existed between the levels of the three hormones and history of migraine and age.

Methods: Thirty women (mean age \pm SD: $33.5 \pm 7.1$ ) with menstrually-related migraine (MM group) and 30 agedmatched controls (mean age \pm SD: $30.9 \pm 7.9$ ) participated in the exploratory study. Pregnenolone sulfate and pregnanolone serum levels were analysed by liquid chromatography-tandem mass spectrometry, while estradiol levels by enzyme-linked immunosorbent assay.

Results: Serum levels of pregnenolone sulfate and pregnanolone were significantly lower in the MM group than in controls (pregnenolone sulfate: $P=0.0328$; pregnanolone: $P=0.0271$, Student's t-test), while estradiol levels were similar. In MM group, pregnenolone sulfate serum levels were negatively correlated with history of migraine $\left(R^{2}=\right.$ $0.1369 ; P=0.0482)$ and age $\left(R^{2}=0.2826, P=0.0025\right)$ while pregnenolone sulfate levels were not age-related in the control group $\left(R^{2}=0.04436, P=0.4337\right.$, linear regression analysis).

Conclusion: Low levels of both pregnanolone, a positive allosteric modulator of the GABAA receptor, and pregnenolone sulfate, a positive allosteric modulator of the NMDA receptor, involved in memory and learning, could contribute either to headache pain or the cognitive dysfunctions reported in migraine patients. Overall, our results agree with the hypothesis that migraine is a disorder associated with a loss of neurohormonal integrity, thus supporting the therapeutic potential of restoring low neurosteroid levels in migraine treatment.
\end{abstract}

Keywords: Pregnenolone sulfate, Pregnanolone, Estradiol, Migraine, Menstrually-related migraine, Neurosteroid, Neuroactive steroid, Cognitive function, Headache, Pain

\footnotetext{
* Correspondence: anna.ferrari@unimore.it

${ }^{4}$ Department of Biomedical, Metabolic and Neural Sciences, Unit of Medical

Toxicology, Headache Centre and Drug Abuse; University of Modena and

Reggio Emilia, Via del Pozzo, 71, 41124 Modena, Italy

Full list of author information is available at the end of the article
}

\section{$\triangle B M C$}

(c) The Author(s). 2021 Open Access This article is licensed under a Creative Commons Attribution 4.0 International License, which permits use, sharing, adaptation, distribution and reproduction in any medium or format, as long as you give appropriate credit to the original author(s) and the source, provide a link to the Creative Commons licence, and indicate if changes were made. The images or other third party material in this article are included in the article's Creative Commons licence, unless indicated otherwise in a credit line to the material. If material is not included in the article's Creative Commons licence and your intended use is not permitted by statutory regulation or exceeds the permitted use, you will need to obtain permission directly from the copyright holder. To view a copy of this licence, visit http://creativecommons.org/licenses/by/4.0/ The Creative Commons Public Domain Dedication waiver (http://creativecommons.org/publicdomain/zero/1.0/) applies to the data made available in this article, unless otherwise stated in a credit line to the data. 


\section{Introduction}

Altered levels of neurosteroids, by changing the balance between neuroexcitation and neuroinhibition in the central nervous system (CNS), can affect psychiatric and neurological disorders [1]. However, the involvement of neurosteroids in migraine has been little explored. In a previous study, we found lower levels of allopregnanolone, a positive allosteric modulator of the $\gamma$ aminobutyric acid type A (GABAA) receptor, in women with menstrually-related migraine than in controls. These data suggested that the reduced levels of allopregnanolone, an inhibitory neurosteroid, were insufficient to counteract the neuronal hyperexcitability associated with migraine [2], thus contributing to the severity of menstrual related migraine attacks [3]. Indeed, migraine is characterized by generalized neuronal hyperexcitability [4], probably mediated by an increased or impaired glutamate transmission [5]. Therefore, it would also be important to study neuroactive steroids with excitatory functions such as pregnenolone sulfate (pregn-5-en-3 $\beta$-ol20 -one $3 \beta$-sulfate). Actually, this neurosteroid acts as a positive allosteric N-methyl-D-aspartate (NMDA) receptor modulator $[6,7]$ and is a potent stimulator of transient receptor potential melastatin-3 (TRPM3) channels, that function as nociceptors in the somatosensory system [8]. Moreover, at the molecular level, stimulation of TRPM3 channels has been shown to be involved in calcitonin gene-related peptide (CGRP) exocytosis [9, 10].

Fluctuations in estrogen and progesterone during the oestrus cycle affect pain perception and threshold. Estradiol, by increasing the NMDA receptor activity, is excitatory while progesterone is inhibitory [11]. Furthermore, variation of estrogen levels modulate the signalling of the CGRP receptor in the trigeminovascular system $[12,13]$. In the previous study, we found no differences in progesterone levels between women with menstrually-related migraine and non-headache women, but we did not measure estradiol or pregnanolone, an isomer of allopregnanolone, also an agonist of the GABAA receptor [3].

To broaden the study on neurosteroids in menstrually related migraine and, in particular, to investigate the balance between steroids with inhibitory and excitatory functions we determined the serum levels of pregnenolone sulfate, pregnanolone and estradiol in women suffering from menstrually-related migraine, compared them with those in non-headache women and analysed whether the levels of the three hormones correlated with the history of migraine and age.

\section{Methods}

\section{Study population}

We determined the serum concentrations of pregnenolone sulfate, estradiol and pregnanolone in the same samples in which we had previously determined other neuroactive hormones (allopregnanolone, progesterone and testosterone) [3]. Therefore, this exploratory study had involved 30 women (mean age \pm SD: $33.5 \pm 7.1$; range 19-45; mean years of migraine \pm SD: $17.4 \pm 8.9$ years) diagnosed with menstrually-related migraine according to the diagnostic criteria of the International Classification of Headache Disorders 3rd edition (ICHD3, appendix, A1.1.2) [14] (MM group) and 30 nonheadache, age-matched women, as controls (mean age \pm SD: $30.9 \pm 7.9$; range $18-44$ ).

Only women with no medical or psychiatric comorbidities and who were not taking migraine prophylaxis, hormone therapies or other drugs capable of modifying neurosteroid levels were included in the study. The MM group was enrolled among the patients of the Headache Center of the University Hospital of Modena (Italy); controls were acquaintances of the patients. The subjects were enrolled from July 2018 to May 2019. All the women provided written consent to participate in the study which was approved by the Ethics Committee of the Area Vasta Emilia Nord (AVEN, Italy) (prot. 0013510/18). Study design and enrollment's procedures are described in detail in our previous publication [3].

\section{Data collection and procedure}

For each subject, personal data, lifestyle habits, clinical history and, for the migraine group, also the history of migraine were collected. Fasting blood samples were collected between day 7 and day 10 of the menstrual cycle and at least two days after the last migraine attack. The samples were allowed to clot at room temperature for 1 $\mathrm{h}$ and then centrifuged at $2000 \mathrm{x} \mathrm{g}$ for $10 \mathrm{~min}$ at $+4{ }^{\circ} \mathrm{C}$ to collect sera.

\section{Quantitative determination of pregnenolone sulfate and pregnanolone by liquid chromatography-tandem mass spectrometry (LC-MS/MS)}

Quantitative determination of pregnenolone sulfate and pregnanolone, which present a keto-group in their moieties, was performed as previously described [3]. Briefly, serum samples were added with deuterated internal standard (IS), vortexed and treated with acetonitrile/ methanol $(70 / 30 ;+1.0 \%$ formic acid $)$ to precipitate proteins. The obtained supernatants were subjected to solid phase extraction procedure to remove endogenous phospholipids and evaporated to dryness. The residues were then derivatized with Amplifex Keto Reagent and analysed by LC-MS/MS on a Kinetex XB-C18 column with a mobile phase of water/acetonitrile $(+3 \mathrm{mM}$ ammonium formate, $+0.1 \%$ formic acid) under gradient elution. Compounds were detected in multiple reaction monitoring mode by acquiring three selected MS/MS transitions for each analyte and IS. Serum levels of the target analytes were determined via the calibration 
curves calculated by analysing blank albumin samples, spiked with known amounts of the target analytes and IS and purified as described above ( $\mathrm{x}=$ concentration; $\mathrm{y}=$ analyte signal/IS signal ratio). Calibration range was $4.00-120 \mathrm{ng} / \mathrm{ml}$ and $0.02-0.65 \mathrm{ng} / \mathrm{ml}$ for pregnenolone sulfate and pregnanolone, respectively, and limit of quantitation values were $0.010 \mathrm{ng} / \mathrm{mL}$ and $0.006 \mathrm{ng} / \mathrm{mL}$ for pregnenolone sulfate and pregnanolone, respectively.

\section{Quantitative determination of estradiol by enzyme-linked Immunosorbent assay (ELISA)}

Estradiol, whose molecule lacks a carbonyl group, does not respond to Amplifex derivatization. On the other hand, direct LC-MS/MS analysis of non-derivatized estradiol does not provide sufficient sensitivity to detect low concentrations. Consequently, the enzyme immunoassay technique was employed for the quantitative measurement of estradiol in serum using a commercial kit (Estradiol sensitive ELISA, Demeditec, Germany), following the protocol reported by the manufacturer. The data were acquired on a microplate reader (Multiscan FC, Thermo Scientific, USA) by measuring the absorbance at $\lambda=450 \mathrm{~nm}$. Estradiol concentrations were determined from a standard curve generated with calibrators included in the kit (calibration range: $1.4-200 \mathrm{pg} / \mathrm{mL}$; limit of quantitation: $1.4 \mathrm{pg} / \mathrm{mL}$ ).

\section{Statistical analysis}

Serum levels of pregnenolone sulfate, pregnanolone and estradiol determined in the MM group were compared with those found in the control group by Student's t-test for independent samples. Effect sizes were calculated using Cohen's d to compare magnitude of the difference of the means and considered as small (0.2), medium (0.5) and large (0.8). The relationship between the levels of the three hormones (independent variables) with migraine years and age was assessed by linear regression analysis. Statistical analysis was carried out by StataIC 13 software. Differences were considered significant if $P$ value (two-tailed) was lower than 0.05 .

\section{Results}

In the MM group, both pregnenolone sulfate $(39.58 \pm$ 18.36) and pregnanolone $(0.09 \pm 0.06)$ serum levels ( $\mathrm{ng} /$ $\mathrm{mL}$, mean $\pm \mathrm{SD}$ ) were significantly lower than in the control group (pregnenolone sulfate: $55.82 \pm 31.79, P=$ 0.0328 ; pregnanolone: $0.16 \pm 0.11, P=0.0271$, Student's $\mathrm{t}$-test). The size of the differences between MM and controls determined by Cohen's d value was medium for pregnenolone sulfate $(-0.64)$ and large for pregnanolone $(-0.82)$. Serum levels $(\mathrm{pg} / \mathrm{mL}$, mean $\pm \mathrm{SD})$ of estradiol were similar between MM $(90.02 \pm 59.22)$ and control $(67.52 \pm 41.12)$ groups $(P=0.1538$, Student's t-test $)$.
In the MM group (Fig. 1) pregnenolone sulfate serum levels were negatively correlated with history of migraine $\left(\mathrm{R}^{2}=0.1369 ; \quad P=0.0482\right)$ and age $\left(\mathrm{R}^{2}=0.2826, \quad P=\right.$ $0.0025)$ while pregnenolone sulfate levels were not agerelated in the control group $\left(R^{2}=0.04436, P=0.4337\right.$, linear regression analysis). The levels of pregnanolone and estradiol in the MM group showed no correlation with history of migraine (pregnanolone: $\mathrm{R}^{2}=0.01091$, $P=0.5897$; estradiol: $\left.R^{2}=0.04694, P=0.2777\right)$ and age (pregnanolone: $\mathrm{R}^{2}=0.02108, P=0.4524$; estradiol: $\mathrm{R}^{2}=$ $0.02805, P=0.4037)$. Even in the control group, pregnanolone and estradiol levels showed no correlation with age (pregnanolone: $\mathrm{R}^{2}=0.01182, P=0.6997$; estradiol: $\mathrm{R}^{2}=0.001884, P=0.8779$, linear regression analysis).

\section{Discussion}

Neuroactive steroids modulate a broad spectrum of neuronal functions including cognition, memory and pain perception. In particular, pregnenolone sulfate acts as a cognitive enhancer by improving learning and memory $[1,15]$ and reduced pregnenolone sulfate levels could be involved in the cognitive dysfunction and memory problems reported in migraine patients [16]. Accordingly, in $\mathrm{MM}$ women the serum levels of pregnenolone sulfate (Fig. 1) correlated inversely with the history of migraine and age, while in the control group no correlation with age was present. Therefore, we believe that migraine and its persistence over the years, rather than the age alone, were associated with progressively decreased levels of pregnenolone sulfate.

The levels of pregnanolone were also significantly lower in MM compared to the control group, in accordance with the previously detected low concentrations of allopregnanolone [3], but they did not correlate with the history of migraine or age. This data can be explained bearing in mind that the production routes of the two hormones are different [17].

As we did not find any differences for progesterone in the previous study [3], the levels of estradiol in the follicular phase were similar between MM and control groups and did not correlate with the history of migraine or age. In contrast, estradiol levels in the luteal phase were reported to be significantly lower in patients suffering from menstrually-related migraine than in healthy controls [18].

Our study has some limitations. The main one was that the determinations were performed in peripheral blood and the ability of pregnenolone sulfate to penetrate the blood brain barrier (BBB) is questionable. It could simply contribute to the neuroactive steroid pool or penetrate the BBB via transporter proteins [19]. However, circulating pregnenolone sulfate has been observed to affect pregnenolone concentration in the CNS in humans [17]. Finally, peripheral levels of 


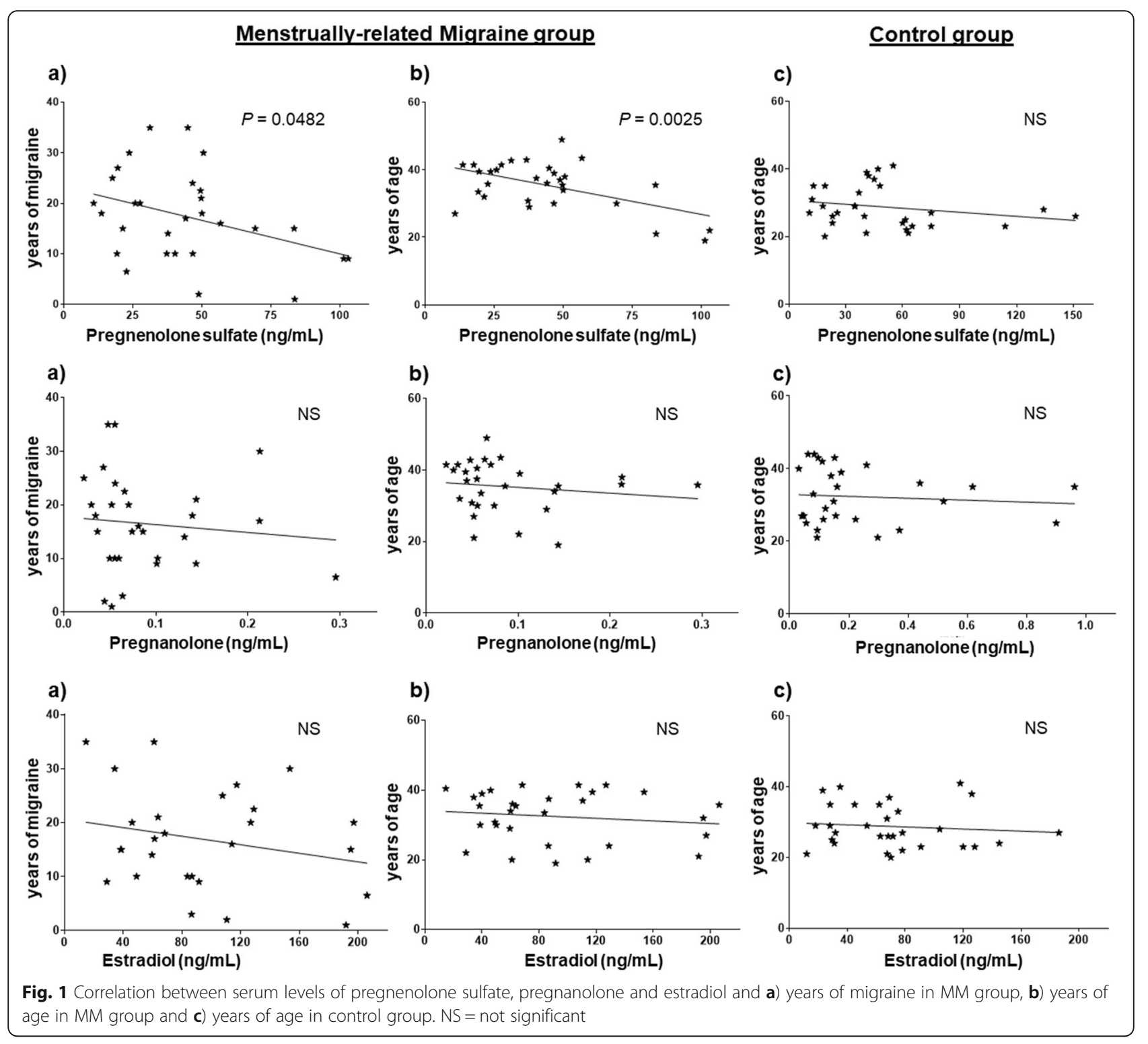

allopregnanolone and pregnenolone have been shown to be positively correlated with gray matter thickness in multiple regions of the cerebral cortex [20]. Ours was an exploratory study, of limited number and therefore our results need to be confirmed in a wider series. We did not perform cognitive tests in the two studied groups, which however did not differ in demographic characteristics and comorbidities. In addition, the levels of pregnenolone sulfate in the control group agreed with those reported in the literature for healthy subjects [1, 21], while no other published data are available for levels in migraine.

Overall, the current results concerning lower levels for pregnenolone sulfate and pregnanolone and our previous results for lower allopregnanolone serum levels in MM group versus control group (see Additional Table) [3] agree with the hypothesis that migraine is a disorder associated with a loss of neurohormonal integrity [22]. In fact, it has been observed that severe pain causes hyper-excitation of the hypothalamus-pituitary-adrenal system which results in high levels of serum hormones such as adrenocorticotropin, cortisol and pregnenolone. If the severe pain continues, however, the system cannot maintain its normal hormone production and the serum levels of some hormones can drop below the normal range [23].

In conclusion, the reduction in peripheral levels of neuroactive steroids in women with menstrually-related migraine (Fig. 2), influencing the neurosteroid pool in 


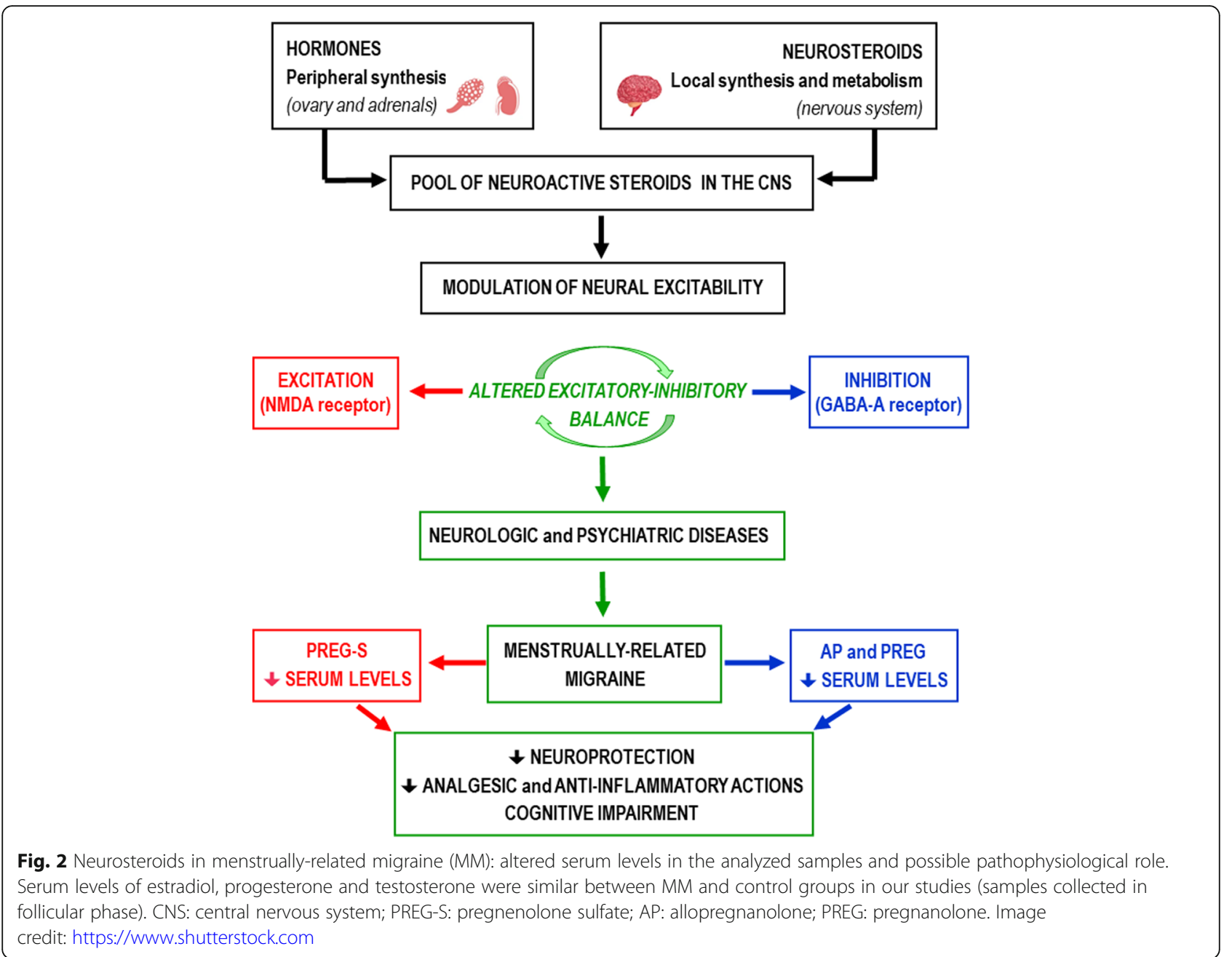

the CNS and the activity of neuronal networks, could contribute either to headache pain or the cognitive dysfunctions reported in migraine $[16,24,25]$. Consequently, restoring low endogenous neurosteroid levels could exhibit therapeutic potential in migraine management.

\section{Abbreviations}

MM: Menstrually-related migraine; CNS: Central nervous system; GABAA: $\gamma^{-}$ aminobutyric acid type A; NMDA: N-methyl-D-aspartate; TRPM3: Transient receptor potential melastatin-3; CGRP: Calcitonin gene-related peptide; ICHD3: International Classification of Headache Disorders 3rd edition; LC-MS/

MS: Liquid chromatography-tandem mass spectrometry; IS: Internal standard; ELISA: Enzyme-Linked Immunosorbent Assay; BBB: Blood brain barrier

\section{Supplementary Information}

The online version contains supplementary material available at https://doi. org/10.1186/s10194-021-01231-9.

\section{Additional file 1.}

\section{Acknowledgements}

The authors wish to thank the "Centro Interdipartimentale Grandi Strumenti" (CIGS) of the University of Modena and Reggio Emilia for technical assistance. LC-MS/MS instruments at CIGS were granted by the Foundation "Fondazione Cassa di Risparmio di Modena - FCRM" (Italy).

Authors' contributions

All authors participated in study design, performed research, data analysis, and drafting of manuscript content. All authors reviewed and approved the manuscript.

\section{Funding}

This study was carried out by research funds from the University of Modena and Reggio Emilia (Italy) attributed to Dr. Anna Ferrari

Availability of data and materials

Anonymized data operated or analysed during this study are available from the Authors upon reasonable request.

\section{Declarations}

Ethics approval and consent to participate

All women participants in this study gave their written consent. The research was conducted in accordance with the ethical principles of the Helsinki Declaration, last edition (2013) and approved by the Ethics Committee of Area Vasta Emilia Nord (AVEN, Italy) (prot. 0013510/18).

Consent for publication

Not applicable. 


\section{Competing interests}

The Authors declare that there is no conflict of interest.

\begin{abstract}
Author details
'Department of Life Sciences, University of Modena and Reggio Emilia, Modena, Italy. ${ }^{2}$ Department of Surgery, Medicine, Dentistry and Morphological Sciences with Transplant Surgery, Oncology and Regenerative Medicine Relevance, University of Modena and Reggio Emilia, Modena, Italy. ${ }^{3}$ School of Pharmacology and Clinical Toxicology, University of Modena and Reggio Emilia, Modena, Italy. ${ }^{4}$ Department of Biomedical, Metabolic and Neural Sciences, Unit of Medical Toxicology, Headache Centre and Drug Abuse; University of Modena and Reggio Emilia, Via del Pozzo, 71, 41124 Modena, Italy.
\end{abstract}

Received: 28 December 2020 Accepted: 15 March 2021 Published online: 23 March 2021

\section{References}

1. Ratner MH, Kumaresan V, Farb DH (2019) Neurosteroid actions in memory and neurologic/neuropsychiatric Disorders. Front Endocrinol (Lausanne) 10: 169

2. Younis $S$, Christensen $C E$, Vestergaard $M B$, Lindberg $U$, Tolnai $D$, Paulson $O B$, et al (2021) Glutamate levels and perfusion in pons during migraine attacks: a $3 T$ MRI study using proton spectroscopy and arterial spin labeling. J Cereb Blood Flow Metab. 41(3):604-616. https://doi.org/10.1177/0271678X2 0906902.

3. Rustichelli C, Bellei E, Bergamini S, Monari E, Baraldi C, Castro FL, Tomasi A, Ferrari A (2020) Serum levels of allopregnanolone, progesterone and testosterone in menstrually-related and postmenopausal migraine: a crosssectional study. Cephalalgia. 40(12):1355-1362. https://doi.org/10.1177/ 0333102420937742

4. Burstein R, Noseda R, Borsook D (2015) Migraine: multiple processes, complex pathophysiology. J Neurosci 35(17):6619-6629. https://doi.org/10.1 523/JNEUROSCI.0373-15.2015

5. Hoffmann J, Charles A (2018) Glutamate and its receptors as therapeutic targets for migraine. Neurotherapeutics. 15(2):361-370. https://doi.org/10.1 007/s13311-018-0616-5

6. Chisari M, Wilding TJ, Brunwasser S, Krishnan K, Qian M, Benz A, Huettner JE, Zorumski CF, Covey DF, Mennerick S (2019) Visualizing pregnenolone sulfate-like modulators of NMDA receptor function reveals intracellular and plasma-membrane localization. Neuropharmacology. 144:91-103. https:// doi.org/10.1016/j.neuropharm.2018.10.015

7. Hrcka Krausova B, Kysilov B, Cerny J, Vyklicky V, Smejkalova T, Ladislav M, Balik A, Korinek M, Chodounska H, Kudova E, Vyklicky L (2020) Site of action of brain neurosteroid pregnenolone sulfate at the $\mathrm{N}$-methyl-D-aspartate receptor. J Neurosci 40(31):5922-5936. https://doi.org/10.1523/JNEUROSCI.3 010-19.2020

8. Méndez-Reséndiz KA, Enciso-Pablo Ó, González-Ramírez R, Juárez-Contreras R, Rosenbaum T, Morales-Lázaro SL (2020) Steroids and TRP channels: a close relationship. Int J Mol Sci 21(11):3819. https://doi.org/10.3390/ ijms21113819

9. Thiel G, Rubil S, Lesch A, Guethlein LA, Rössler OG (2017) Transient receptor potential TRPM3 channels: pharmacology, signaling, and biological functions. Pharmacol Res 124:92-99. https://doi.org/10.1016/j.phrs.2017.07. 014

10. Benemei S, Dussor G (2019) TRP channels and migraine: recent developments and new therapeutic opportunities. Pharmaceuticals 12(2):54

11. Finocchi C, Strada L (2014) Sex-related differences in migraine. Neurol SCi 35(Suppl 1):207-213. https://doi.org/10.1007/s10072-014-1772-y

12. Labastida-Ramírez A, Rubio-Beltrán E, Villalón CM, MaassenVanDenBrink A (2019) Gender aspects of CGRP in migraine. Cephalalgia. 39(3):435-444. https://doi.org/10.1177/0333102417739584

13. Cupini LM, Corbelli I, Sarchelli P (2020) Menstrual migraine: what it is and does it matter? J Neurol. https://doi.org/10.1007/s00415-020-09726-2

14. (2018) Headache classification Committee of the International Headache Society (IHS) the international classification of headache disorders, 3rd edition. Cephalalgia. 38(1):1-211. https://doi.org/10.1177/0333102417738202

15. Belelli D, Hogenkamp D, Gee KW, Lambert JJ (2020) Realising the therapeutic potential of neuroactive steroid modulators of the GABAA receptor. Neurobiol Stress 12:100207. https://doi.org/10.1016/j.ynstr.2019.1 00207
16. Vuralli D, Ayata C, Bolay H (2018) Cognitive dysfunction and migraine. J Headache Pain 19(1):109. https://doi.org/10.1186/s10194-018-0933-4.

17. Kancheva R, Hill M, Novák Z, Chrastina J, Kancheva L, Stárka L (2011) Neuroactive steroids in periphery and cerebrospinal fluid. Neuroscience. 191:22-27. https://doi.org/10.1016/j.neuroscience.2011.05.054

18. Ibrahimi K, van Oosterhout WPJ, van Dorp W, Danser AHJ, Garrelds IM, Kushner SA, Lesaffre EMEH, Terwindt GM, Ferrari MD, van den Meiracker AH, MaassenVanDenBrink A (2015) Reduced trigeminovascular cyclicity in patients with menstrually related migraine. Neurology. 84(2):125-131. https://doi.org/10.1212/WNL.0000000000001142

19. Grube M, Hagen P, Jedlitschky G (2018) Neurosteroid transport in the brain: role of $A B C$ and SLC transporters. Front Pharmacol 9:354. https://doi.org/1 0.3389/fphar.2018.00354

20. Morey RA, Davis SL, Haswell CC, Naylor JC, Kilts JD, Szabo ST, Shampine LJ, Parke GJ, Sun D, Swanson CA, Wagner HR, Mid-Atlantic MIRECC Workgroup, Marx CE (2019) Widespread cortical thickness is associated with neuroactive steroid levels. Front Neurosci 13:1118. https://doi.org/10.3389/fnins.2019. 01118

21. Heydari B, Le Mellédo J-M (2002) Low pregnenolone sulphate plasma concentrations in patients with generalized social phobia. Psychol Med 32(5):929-933. https://doi.org/10.1017/s0033291702005238

22. Dzugan SA, Dzugan KS (2015) Is migraine a consequence of a loss of neurohormonal and metabolic integrity? A new hypothesis. Neuro Endocrinol Lett 36(5):421-429

23. Tennant $F(2013)$ The physiologic effects of pain on the endocrine system Pain Ther 2(2):75-86. https://doi.org/10.1007/s40122-013-0015-x

24. Santangelo G, Russo A, Tessitore A, Garramone F, Silvestro M, Della Mura MR, Marcuccio L, Fornaro I, Trojano L, Tedeschi G (2018) Prospective memory is dysfunctional in migraine without aura. Cephalalgia. 38(12):18251832. https://doi.org/10.1177/0333102418758280

25. Gil-Gouveia R, Martins IP (2019) Cognition and cognitive impairment in migraine. Curr Pain Headache Rep 23(11):84. https://doi.org/10.1007/s11916019-0824-7

\section{Publisher's Note}

Springer Nature remains neutral with regard to jurisdictional claims in published maps and institutional affiliations.

Ready to submit your research? Choose BMC and benefit from:

- fast, convenient online submission

- thorough peer review by experienced researchers in your field

- rapid publication on acceptance

- support for research data, including large and complex data types

- gold Open Access which fosters wider collaboration and increased citations

- maximum visibility for your research: over $100 \mathrm{M}$ website views per year

At $\mathrm{BMC}$, research is always in progress.

Learn more biomedcentral.com/submissions 